\title{
Guillain-Barré syndrome and adjuvanted pandemic influenza A (H1N1) 2009 vaccine: multinational case-control study in Europe
}

\author{
Jeanne Dieleman senior pharmacoepidemiologist ${ }^{1}$, Silvana Romio senior medical statistician ${ }^{1}$, Kari \\ Johansen senior infectious diseases scientist ${ }^{2}$, Daniel Weibel senior epidemiologist ${ }^{3}$, Jan Bonhoeffer \\ consultant in infectious diseases and vaccines ${ }^{3}$, Miriam Sturkenboom professor of \\ pharmacoepidemiology and medical informatics ${ }^{1}$, and the VAESCO-GBS Case-Control Study Group
}

${ }^{1}$ Department of Medical Informatics, Erasmus University Medical Center, Rotterdam, Netherlands; ${ }^{2}$ European Centre for Disease Prevention and Control, ECDC, Stockholm, Sweden; ${ }^{3}$ Brighton Collaboration, Basel, Switzerland

\begin{abstract}
Objective To assess the association between pandemic influenza A (H1N1) 2009 vaccine and Guillain-Barré syndrome.

Design Case-control study.

Setting Five European countries

Participants 104 patients with Guillain-Barré syndrome and its variant Miller-Fisher syndrome matched to one or more controls. Case status was classified according to the Brighton Collaboration definition. Controls were matched to cases on age, sex, index date, and country.
\end{abstract}

Main outcome measures Relative risk estimate for Guillain-Barré syndrome after pandemic influenza vaccine.

Results Case recruitment and vaccine coverage varied considerably between countries; the most common vaccines used were adjuvanted (Pandemrix and Focetria). The unadjusted pooled risk estimate for all countries was 2.8 (95\% confidence interval 1.3 to 6.0). After adjustment for influenza-like illness/upper respiratory tract infection and seasonal influenza vaccination, receipt of pandemic influenza vaccine was not associated with an increased risk of Guillain-Barré syndrome (adjusted odds ratio $1.0,0.3$ to 2.7 ). The $95 \%$ confidence interval shows that the absolute effect of vaccination could range from one avoided case of Guillain-Barré syndrome up to three excess cases within six weeks after vaccination in one million people.

Conclusions The risk of occurrence of Guillain-Barré syndrome is not increased after pandemic influenza vaccine, although the upper limit does not exclude a potential increase in risk up to 2.7-fold or three excess cases per one million vaccinated people. When assessing the association between pandemic influenza vaccines and Guillain-Barré syndrome it is important to account for the effects of influenza-like illness/upper respiratory tract infection, seasonal influenza vaccination, and calendar time.

\section{Introduction}

During the 2009 influenza A (H1N1) pandemic, new monovalent adjuvanted and non-adjuvanted pandemic influenza A (H1N1) vaccines were introduced in Europe. Documented immunogenicity and safety was in line with the CHMP Note for Guidance, but safety data were limited..$^{1-8}$ Vaccination campaigns started in autumn 2009 at the peak of the pandemic in Europe.

A concern with the pandemic influenza A (H1N1) 2009 vaccine was the possible occurrence of neuroimmunological adverse events, including Guillain-Barré syndrome. A more than sevenfold increased risk of Guillain-Barré syndrome was observed with the swine origin influenza A (H1N1) subtype A/NJ/76 vaccine applied in the United States in $1976,{ }^{9}$ when the vaccination campaign had to be discontinued abruptly. Subsequent prospective surveillance studies ${ }^{10}{ }^{11}$ and retrospective epidemiological studies ${ }^{12}{ }^{13}$ on seasonal influenza vaccines used in 1978, 1979, 1980, 1992, 1993, and beyond showed no or modest increases (up to twofold) in risk of Guillain-Barré syndrome. Even though the studies repeatedly showed risk estimates well below the sevenfold increase of 1976, they do not provide reassurance that there is no increase in risk after seasonal influenza vaccination. Small increases might surface only during mass vaccination campaigns.

Guillain-Barré syndrome is an acute polyneuropathy, which, in Europe, mostly presents as acute inflammatory demyelinating polyradiculoneuropathy leading to progressive symmetrical paresis. ${ }^{14-16}$ Guillain-Barré syndrome is fatal in $3-10 \%$ of cases and leads to disability for more than six months in $20 \% .{ }^{17}$ The risk increases with age; reported incidence rates range between 0.4 and 4 per 100000 person years. $^{18}$ 
The pathogenesis of the syndrome is not fully understood, but it is usually preceded by specific gastrointestinal and respiratory infections. ${ }^{19-21}$ Some infections might induce the production of cross reactive antibodies to neural gangliosides ${ }^{22}$ which cause inflammatory neural damage. In 2008, Nachamkin et al reported that 1976 influenza A (H1N1) vaccine was capable of inducing cross reactive anti-GM1 in mice, supporting a causal relation between the vaccination and Guillain-Barré syndrome. ${ }^{23}$

To date the role of influenza vaccinations as a trigger in Guillain-Barré syndrome remains controversial. Two recent studies from the United Kingdom found no supporting evidence for a causal relation but rather identified influenza-like illness as a strong risk factor. ${ }^{21}{ }^{24}$ The results suggested a protective effect of seasonal vaccination, possibly through the prevention of influenza-like illness. ${ }^{21}$

Prospective monitoring of vaccine safety is essential in maintaining public trust in vaccination campaigns. ${ }^{25}$ This and the issues around Guillain-Barré syndrome in 1976 led the European Centre for Disease Prevention and Control to commission a prospective evaluation of any association between pandemic influenza vaccines and Guillain-Barré syndrome.

\section{Methods}

\section{Setting}

The VAESCO (Vaccine Adverse Events Surveillance and Communication) consortium conducted a distributed case-control study. VAESCO is a growing network of organisations (public health institutes, regulatory agencies, and academic research centres) in Europe dedicated to improving monitoring of safety of vaccines after licensing and was initiated by the European Centre for Disease Prevention and Control.

Centres in Denmark, France, the Netherlands, Sweden, and the UK participated in this study. The respective databases captured a total source population of 50 million. All centres worked according to a common protocol with a standardised case definition and data collection form. Data were entered locally through a common electronic data entry system. At each centre, transformations were done by a standardised JAVA based program (Jerboa version 2.6.0, Erasmus University Medical Center, Rotterdam, Netherlands), which was verified by an independent statistician (SR) ${ }^{26}$ Only completely anonymous and de-identified datasets with no individual dates of disease or exposure were shared for data pooling and centralised analysis. Consent forms, original data, and Jerboa input files were kept locally. Because of differences in healthcare structure and availability of registries, the type of source population from which cases and controls were recruited and the type of data sources differed by country (see table 1 ). The coordinating centre closely verified and queried data quality. The coordinating centre and the national lead investigators ensured that, as far as possible, information was collected in the same way from cases and controls. The study period ran between 1 November 2009 and 30 March 2010.

\section{Cases and controls}

For this study we included cases of Guillain-Barré syndrome and its variant Miller-Fisher syndrome. Each case was validated according to the Brighton Collaboration definition of Guillain-Barré syndrome, based on information obtained from the reporting neurologist (France, Sweden, and Netherlands) or from data in charts (UK, Denmark). ${ }^{14}$ All cases fulfilling the case definition for Guillain-Barré syndrome or Miller Fisher syndrome level 1-3 were included as well as any other cases with a diagnosis confirmed by a neurologist. A sensitivity analysis was conducted in which we restricted the cases to those meeting Brighton Collaboration definition levels 1-3 only. The index date was the earliest date of first symptoms or diagnosis of Guillain-Barré syndrome. Table 1 summarises country specific approaches to identification of cases and controls. Each case was matched to up to 25 controls on age (plus or minus one year), sex, index date, and country.

\section{Exposure classification}

The primary exposure of interest was pandemic influenza vaccination during a risk window of one day to six weeks before the index date. Exposure was further classified according to the brand of vaccine (Pandemrix, Focetria, Celvapan, Panenza, or other) and dose (first or second). Vaccination occurring more than six weeks before was classified as past exposure. ${ }^{9}$ Unknown vaccination dates were categorised separately. Data on pandemic influenza vaccination were obtained from vaccine registries in Denmark and France, from general practitioner records in the UK and the Netherlands, and through structured interviews in Sweden.

\section{Control for confounding}

Information on the following covariates was collected with a standardised data collection form in each country: history of Guillain-Barré syndrome, Epstein-Barr virus infection, malignancy, immunosuppression, autoimmune disorder, gastrointestinal infections, influenza-like illness or upper respiratory tract infection, and other vaccinations (especially seasonal influenza vaccination). For influenza-like illness or upper respiratory tract infection, gastrointestinal infection, and seasonal influenza vaccination, the risk window comprised the six weeks before the index date, not including the index date itself. Seasonal influenza vaccination (2009-10 season) more than six weeks before the index date was classified as past exposure. Information on covariates was retrieved from general practice records in the UK and the Netherlands, from hospital medical records in France, and by structured interview in Sweden. In Denmark, information on covariates was obtained through chart review of the cases only and therefore could not be used for statistical adjustments.

\section{Statistical analysis}

Matched odds ratios and 95\% confidence intervals were calculated with multivariate conditional logistic regression. "No vaccination" in the six weeks before the index date served as the reference category. Variables considered for inclusion in the final model were those that were associated with Guillain-Barré syndrome in the univariate matched analysis at $\mathrm{P}<0.1$; they were retained in the final model if they changed the point estimate of the association between the pandemic influenza vaccine and Guillain-Barré syndrome by more than $10 \% .{ }^{27} \mathrm{We}$ conducted age stratified analyses to estimate the association with pandemic influenza vaccination in different age groups. We explored interactions between pandemic influenza vaccination and the main confounders by applying population restrictions but had insufficient power for statistical testing because of the low prevalence of exposure.

We carried out sensitivity analyses regarding disease and misclassification of exposure to pandemic influenza vaccination to assess robustness of the results. Exposure misclassification was addressed with three approaches: with all people with unknown dates of vaccination considered as exposed; with all people with unknown dates of vaccination considered as 
unexposed; and with all exposures more than six weeks before classified as non-exposure.

Risk estimates across countries were pooled with a meta-analytical approach to account for the differences in exposure prevalence. We used a random effects model to account for heterogeneity between countries. ${ }^{28}$ For all analyses significance was accepted at a two sided $\mathrm{P}<0.05$. Analyses were done in SPSS 15.0 for windows (release 15.0, 2006, SPSS, Chicago, IL).

\section{Results \\ Study population}

From a source population of about 50 million in the five countries, 154 cases of Guillain-Barré syndrome were identified. Of these, 104 could be matched to one or more controls. Many unmatched cases were from France, where timely recruitment of controls was problematic. Comparison of the number of patients with Guillain-Barré syndrome in hospital claims registries in the Netherlands suggested around 50\% under-reporting of cases omitted for the study. The uptake of pandemic influenza A (H1N1) 2009 vaccine in excluded cases was similar to that in the included cases.

Most cases were men, aged 46-61 (table 2) and had Brighton Collaboration case classification level 1 to 3 . In countries with retrospective chart or medical record review (Denmark and UK) the available information did not always allow for Brighton Collaboration classification, mostly because information regarding symptoms and diagnostic processes was not recorded to the required level of detail and could not be retrieved retrospectively. Acute inflammatory demyelinating polyradiculoneuropathy was the most common type of Guillain-Barré syndrome. Six patients $(5.8 \%)$ had a disability score of 5 (ventilator treatment required) or 6 (fatal).

Chronic comorbidity was rare; malignancy and immunocompromise were the most common comorbid conditions, but these were not associated with Guillain-Barré syndrome. Acute infections in the six weeks leading up to the index date were more common and occurred mostly in cases (table 3). Most infections were influenza-like illness/upper respiratory tract infections. They were strongly associated with Guillain-Barré syndrome, with odds ratios ranging from 4.9 ( $95 \%$ confidence interval 1.6 to 15.5 ) in the UK to 19.3 (5.9 to 63.4) in the Netherlands.

\section{Vaccinations}

Pandemrix was the most widely used pandemic influenza A (H1N1) 2009 vaccine in the study population as this was the main brand used in Denmark, Sweden, and the UK. In the Netherlands Focetria was the predominant vaccine, but Pandemrix was used in children aged below 6. Other brands were used only rarely. Vaccine uptake was highest in the Netherlands and Sweden and was much lower $(<10 \%$ of study population) in the UK, Denmark, and France (table 4). In each country, exposure to the vaccine in unmatched cases was similar to that in matched cases. Exposure prevalence among unreported cases in the Netherlands was similar to that of cases in the study.

Seasonal influenza vaccination coverage in the Netherlands was similar to pandemic influenza vaccination coverage but consistently occurred earlier and therefore was more often classed as past exposure (table 4). In the UK seasonal influenza vaccination was more common than pandemic influenza vaccination, and there was evidence of an increased risk of Guillain-Barré syndrome with recent exposure to seasonal influenza vaccination (odds ratio 6.3 (1.8 to 22.0) with no adjustment for influenza-like illness/upper respiratory tract infections; 5.1 (1.4 to 18.6) with adjustment). In Sweden the recorded uptake of seasonal influenza vaccination was low and potentially incomplete. For Denmark and France, no information on seasonal influenza vaccination was available for controls. No cases were exposed to other types of vaccination in the six weeks before the index date.

\section{Guillain-Barré syndrome and pandemic influenza vaccination}

Unadjusted matched analyses resulted in risk estimates for Guillain-Barré syndrome with pandemic influenza vaccination that ranged from 1.3 to 2.5 in the UK, Sweden, and Netherlands (table 5). The risk estimate in Denmark, based on two exposed cases, was 9.5 (1.7 to 53). Both cases had extensive comorbidity but no influenza-like illness/upper respiratory tract infections or gastrointestinal infections recorded in the charts. We could not calculate an estimate for France because there was only one exposed case and no exposed controls. There was no difference in risk between Pandemrix and Focetria, although the products could not be compared within countries. Two doses of pandemic influenza vaccination as provided in the Netherlands seemed to be associated with a higher risk of Guillain-Barré syndrome (table 5).

The increase in risk of Guillain-Barré syndrome associated with pandemic influenza vaccination in the unadjusted analyses disappeared when we adjusted the results for influenza-like illness/upper respiratory tract infections and seasonal influenza vaccination. Adjusted risk estimates for the Netherlands and the UK, where information on both variables was available, were 0.6 (0.1 to 4.4) and 0.7 (0.1 to 4.1), respectively (table 5).

The test for homogeneity in effect estimates across the four countries was not significant $(\mathrm{P}=0.40)$, but, because of lack of power of the test and the differences observed, we used a random effects model for the weighted pooling. The crude matched risk for Guillain-Barré syndrome was 2.8 (1.3 to 6.0). The random effects risk estimate adjusted for seasonal influenza vaccination and influenza-like illness/upper respiratory tract infections for the Netherlands, UK, and Sweden was 1.0 ( 0.3 to $2.7, \mathrm{P}=0.81$ for homogeneity). As Swedish data did not capture seasonal influenza vaccination well and might be subject to selection and recall bias, we conducted a sensitivity analysis without Sweden. The pooled adjusted odds ratio was 0.7 (0.2 to 2.5) (table 6). Denmark could not be included in the adjusted analyses because information on influenza-like illness/upper respiratory tract infections and seasonal influenza vaccination was unavailable for the controls.

\section{Restricted and stratified analyses}

In people without influenza-like illness/upper respiratory tract infections the risk of Guillain-Barré syndrome after pandemic influenza vaccination was higher but not significant and was unstable (table 5). The effect shrank on adjustment for seasonal influenza vaccination. Similarly, influenza-like illness/upper respiratory tract infections had a strong confounding effect in people without seasonal influenza vaccination. As recorded seasonal influenza vaccination in Sweden was possibly incomplete we could explore confounding only by influenza-like illness/upper respiratory tract infections, which again was substantial (matched odds ratio for Swedish population without influenza-like illness/upper respiratory tract infections was 1.3, 0.2 to 8.1$)$. 
Cases in children were rare (9\%, table 2). Most cases were in people aged 19-59 $(n=57,55 \%)$, in whom uptake of pandemic influenza A (H1N1) 2009 vaccine was low (exposure in controls $4 \%)$. Uptake of the vaccine was higher in those aged over 60 (10\% in controls). Risk estimates for those aged 19-59 and 60 and over did not differ significantly (4.9 (1.3 to 17.9) $v 2.7$ (0.8 to 9.1$)$ ). Below the age of 19 the risk estimate seemed high but this was unstable because of too few exposed people (one case and two controls).

\section{Sensitivity analyses}

We carried out various sensitivity analyses to assess the impact of misclassification of the outcome and exposure as well as residual confounding. Restricting the cases to Brighton Collaboration case classification levels 1 to 3 did not materially alter the risk estimates (pooled random effects adjusted odds ratio $0.9,0.2$ to 4.6$)$. Extending the risk window for pandemic influenza A (H1N1) 2009 vaccine to any time before the index date reduced this to 0.7 (0.3 to 1.9). Considering people with missing dates of pandemic influenza vaccination as exposed in the risk window reduced the estimate to 0.8 ( 0.3 to 2.3$)$ as data were missing mostly in controls. Considering them as unexposed had no effect on the estimate. Excluding Sweden (the only country with interview based assessment of exposure and covariates) from the pooled analyses changed the adjusted pooled random effects estimate from 1.0 to 0.7 (0.2 to 2.5) (table $6)$.

\section{Discussion \\ Principal findings}

In a source population of around 50 million people in Europe we could not find any association between adjuvanted pandemic influenza A (H1N1) 2009 vaccine and Guillain-Barré syndrome (adjusted odds ratio 1.0, 95\% confidence interval 0.3 to 2.7 ).

The increased risk in the unadjusted analyses disappeared when we adjusted for the apparent strong confounding of influenza-like illness/upper respiratory tract infections and seasonal influenza vaccination. Based on the $95 \%$ confidence interval for the adjusted odds ratio it is unlikely that the relative risk is above 2.7. Thus it is unlikely that there would be more than one excess case of Guillain-Barré syndrome per 340000 vaccinated people (or three per million) given a risk window of six weeks and a background incidence rate of 1.5 per 100000 person years.

The effects of adjustment for seasonal influenza vaccination were strong but differed between countries, which could be explained by differences in vaccination strategies. In the Netherlands the population targeted for pandemic influenza A (H1N1) 2009 vaccine overlapped largely with the population targeted for seasonal influenza vaccination, whereas in the UK it only partially overlapped as not all older people were targeted for pandemic influenza A (H1N1) 2009 vaccination. In Sweden, pandemic influenza A (H1N1) 2009 vaccine was made available to the entire population, but there was under-reporting of seasonal influenza vaccination so that we could not appropriately adjust for it.

\section{Relation to other studies}

The VAESCO consortium is one of the first groups to provide data on the association between pandemic influenza A (H1N1) 2009 vaccines and Guillain-Barré syndrome with substantial power and mostly adjuvanted vaccines. Our results are comparable with those of a study investigating the risk of
Guillain-Barré syndrome with non-adjuvanted pandemic influenza A (H1N1) 2009 vaccine in the US, which showed an age adjusted rate ratio of 1.77 (1.12 to 2.56$).{ }^{29}$ In the US Vaccine Safety Datalink no increased risk of adverse events was identified after administration of 1195552 doses of non-adjuvanted vaccine to people aged under 18 and 4773956 doses to adults. ${ }^{30}$ Those studies made no statistical adjustment for influenza-like illness/upper respiratory tract infections and seasonal influenza vaccination.

Influenza-like illness/upper respiratory tract infections are a recognised risk factor for Guillain-Barré syndrome, ${ }^{16}$ as confirmed in our study. The association with influenza-like illness shown previously in the UK General Practice Research Database was stronger (18.0 (7.5 to 46.4) for influenza-like illness and 5.2 (3.5 to 7.6) for acute respiratory tract infections) than in our study (4.9 (1.6 to 15.5$)$ for influenza-like illness/upper respiratory tract infections and predominantly comprising upper respiratory tract infections). ${ }^{21}$

Several vaccines have been associated with Guillain-Barré syndrome, ${ }^{31-33}$ but controversy remains for the influenza vaccines. ${ }^{912} 13203435$ A recent study found no association between seasonal influenza vaccination and Guillain-Barré syndrome, ${ }^{24}$ whereas our study showed an increased risk. Different circumstances and differences in study design could explain this discrepancy. The previous study was a self controlled case series, had differential case verification, and used data up to 2005. In 2009, during the study period of the present study, seasonal influenza vaccinations were supplied while the pandemic was coming to its peak. As in most countries pandemic influenza vaccines became available only after the seasonal vaccination campaign, people with influenza symptoms might have had a higher uptake of seasonal influenza vaccination. If there was under-reporting of influenza-like illness in the General Practice Research Database, because patients were discouraged to visit the general practitioner for such symptoms in the UK in 2009, seasonal influenza vaccination could therefore be a proxy for influenza-like illness. This could explain why the effect of seasonal influenza vaccination was higher than expected in the General Practice Research Database.

\section{Strengths and weaknesses}

By combining data from several European countries we showed consistency of the risk estimate across countries and we could increase the sample size by pooling data that were collected, transferred, and analysed in a standardised way, reducing heterogeneity between study sites. By pooling through meta-analysis we accounted for population size and differences in exposure prevalence. ${ }^{28}$ Moreover, the differences in data collection between countries allowed us to establish the impact of potential biases.

Because this study was conducted in a pandemic situation it also has limitations, especially given the increased awareness of a potential increase in the risk of Guillain-Barré syndrome associated with pandemic influenza vaccination. As a consequence, people at increased baseline risk (such as those with a history of the syndrome) might be less likely to have received the vaccine and there could have been over-reporting or selective inclusion of exposed people with Guillain-Barré syndrome in the participating countries.

In the Netherlands there was under-reporting of cases, but verification against objective claims data suggested this was non-differential with regards to exposure. In Sweden and France, there were substantial delays in inclusion of cases, and selectiveness could not be fully assessed as data on non-included 
patients were not available. In the UK and Denmark, patient consent was not required, which should reduce the likelihood of differential under-reporting. This assumption, however, could not be verified with the available data. A priori we had assumed that any selection would work in the direction of including more exposed cases as many physicians were aware of the potential risk. The latter would have resulted in an overestimated risk, which does not seem to have affected our study as we did not find an increased risk.

Misclassification of the timing of pandemic influenza A (H1N1) 2009 vaccine, as reflected by the amount of missing information on vaccination, occurred mostly in controls, suggesting more accurate collection of data for cases, especially in Sweden. Sweden was the only country in which exposure was collected by interview rather than a registry, which could have introduced recall bias. Sensitivity analyses addressing this particular issue showed that complete information on all dates would have resulted in even lower risk estimates.

We addressed important confounders by matching (age, sex, calendar time, and country) and by adjusting in a multivariate analysis. Adjustment for influenza-like illness/upper respiratory tract infection and seasonal influenza vaccination had strong effects on the risk estimates and caused the pooled estimate to reduce from 2.8 to 1.0 . Both factors were positively associated with pandemic influenza vaccination and also with Guillain-Barré syndrome. In particular seasonal influenza vaccination and pandemic influenza vaccination were strongly associated with each other and adjustment for seasonal vaccination had the most pronounced effect on the effect estimate, as shown in table 5 , both in the UK and the Netherlands. As argued above, seasonal influenza vaccination could be a proxy for being at high risk for complications associated with influenza or for having influenza symptoms as the seasonal vaccination was supplied at the beginning of the pandemic when there was fear of the consequences and the pandemic influenza vaccination was not yet supplied.

Residual confounding will exist for the countries where information on influenza-like illness/upper respiratory tract infection or seasonal influenza vaccination was (partly) unavailable, such as in Denmark, Sweden (seasonal vaccination), and France. Differential recording of risk factors for Guillain-Barré syndrome cannot be ruled out and hence more information regarding these risk factors might have been available for cases than for controls, especially if cases were recruited through neurologists. This would have resulted in an underestimated risk. Recall bias in the Swedish data cannot be ruled out as information was gathered from cases and controls by interview. In the UK information on covariates was obtained similarly for cases and controls, showing slightly less impact of influenza-like illness/upper respiratory tract infection, and the adjusted risk estimate showed no association. The relatively low impact of influenza-like illness/upper respiratory tract infection on Guillain-Barré syndrome in the UK could also be the consequence of non-differential false negative misclassification of infections: patients were advised not to visit their general practitioner for influenza-like illness.

\section{Meaning of the study}

In our opinion the study contributes at least four pieces of important information. The quantification of the association between Guillain-Barré syndrome and adjuvanted pandemic influenza vaccines allows for subsequent assessment of benefit to risk. Our point estimate shows no association between pandemic influenza vaccination and Guillain-Barré syndrome, although the upper confidence limit is 2.7. In terms of absolute risk, on the basis of the upper confidence limit the absolute risk would be less than three excess cases after one million vaccinations. This is well below the observed increase in risk with the 1976 swine origin influenza A (H1N1) subtype A/NJ/76 vaccine applied in the US, which was reported to be sevenfold. The consistent pattern across countries provides reassurance about the findings. The study also highlights the added value of an international data linkage study with a single protocol, a common data model, and a uniform analysis plan for the assessment of vaccine safety.

\section{Unanswered questions and future research}

Residual confounding by unmeasured patients' characteristics that are not time dependent (such as the underlying reason for being eligible for vaccination) can be studied with a self controlled case series design. VAESCO is finalising such a study of the association between pandemic influenza A (H1N1) 2009 vaccination and Guillain-Barré syndrome in seven countries. The series will include the cases from the study presented here supplemented with unmatched cases and cases from additional countries over a longer period. It will also eliminate any differential recording of confounders between cases and controls.

The coordinating partner for the VAESCO consortium is the Brighton Collaboration. We thank all the VAESCO members and the Brighton Collaboration coordinating staff for their supportive contributions. This study is based in part on data from the Full Feature General Practice Research Database obtained under licence from the UK Medicines and Healthcare products Regulatory Agency. The interpretation and conclusions contained in this report are those of the authors alone. We acknowledge the use of the UK National Grid Service in carrying out this work.

Members of the VAESCO-GBS case-control study group Jeanne P Dieleman (Erasmus University Medical Center, Netherlands), Silvana Romio (Erasmus University Medical Center, Netherlands), Corinne S de Vries (Bath University), Cormac Sammon (Bath University), Nick Andrews (Health Protection Agency), Anders Hviid (Statens Serum Institut, Denmark), Henrik Svanström (Statens Serum Institut, Denmark), Ditte Mølgaard-Nielsen (Statens Serum Institut, Denmark), Maryse Lapeyre-Mestre (University of Toulouse, France), Agnès Sommet (University of Toulouse, France), Christel Saussier (French Medicines Agency, France), Anne Castot (French Medicines Agency, France), Harald Heijbel (Swedish Institute for Infectious Disease Control, Sweden), Lisen Arnheim Dahlström (Karolinska Institutet, Sweden), Jonas Hallgren (Karolinska Institutet, Sweden), Par Sparen (Karolinska Institutet, Sweden), Mees Mosseveld (Erasmus University Medical Center, Netherlands), Martijn Schuemie (Erasmus University Medical Center, Netherlands), Nicoline van der Maas (RIVM, Netherlands), Bart C Jacobs (Erasmus University Medical Center, Netherlands), Kari Johansen (ECDC, Sweden), Piotr Kramarz (ECDC, Sweden), Daniel Weibel (Brighton Collaboration, Switzerland), Jan Bonhoeffer (Brighton Collaboration, Switzerland), and Miriam CJM Sturkenboom (Erasmus University Medical Center, Netherlands).

Contributors: JD, JB, and MS drafted the manuscript; SR, Henrik Svanström, DW, Nick Andrews, JD, and MS discussed and performed the statistical analysis. Martijn Schuemie and Mees Mosseveld developed software to collect and process data for the study. DW and JB coordinated the VAESCO studies and took care of communication and distribution of study materials to group members. Data management was done by JPD, SR and MS. All members of the VAESCO-GBS case-control study group contributed to the collection of data for the study and discussions on the design, conduct and interpretation of the local and pooled findings. They had full access to the data and reviewed 


\section{What is already known on this topic}

The swine origin influenza $A(H 1 N 1)$ subtype $A / N J / 76$ vaccine used in the US in 1976 was associated with a more than sevenfold increased risk of Guillain-Barré syndrome

Subsequent studies repeatedly showed only a slight to no increase in risk after seasonal influenza vaccination during later seasons

In 2009 mass vaccination with new adjuvanted pandemic influenza A (H1N1) 2009 vaccines started in Europe, but it was unknown if these vaccines were associated with an increased risk of Guillain-Barré syndrome

\section{What this study adds}

Adjuvanted pandemic influenza A (H1N1) 2009 vaccines did not increase the risk of Guillain-Barré syndrome substantially, if at all

Influenza-like illness and upper respiratory tract infection are important covariates in the association between influenza vaccination and Guillain-Barré syndrome

Multinational data linkage based on a single protocol, common data model, and uniform analysis plan for collaborative and prospective investigation of important potential vaccine safety issues is feasible

and approved the drafts of the manuscript. Piotr Kramarz and KJ contributed to the discussion of the study design and interpretation of results and reviewed and commented on the manuscript. MS is guarantor.

Funding: This study was funded by the European Centre for Disease Prevention and Control. The VAESCO consortium was funded by the European Centre for Disease Prevention and Control (Specific agreement No 1 to Framework Partnership Agreement No GRANT/2009/003 on a grant for an action, addendum no 1 "Pan Flu Supplement" to specific agreement no 1) for the conduct of safety studies on the new pandemic influenza A (H1N1) vaccine. The GBS case-control study was conducted with part of the funding in work package 4 . The project has received funding from the European Centre for Disease Prevention and Control (ECDC, www.ecdc.europa.eu) through the call for proposal. ECDC uses only public money in funding its projects. Piotr Kramarz and KJ collaborated with the VAESCO Consortium in study design, interpretation of results, and in reviewing and commenting on the manuscript. The European Centre for Disease Prevention and Control also provided support on background information regarding the H1N1-pandemic and vaccination policies.

Competing interests: All authors have completed the Unified Competing Interest form at www.icmje.org/coi_disclosure.pdf (available on request from the corresponding author) and claim no conflict of interest related to the submitted work. The following authors make available additional information, which may be deemed relevant to the submitted work: Piotr Kramarz was employed by Pfizer during 2001-7. KJ received research grants from GSK and SPMSD until 2008. JB has provided scientific advice to GSK and Wyeth/Pfizer. Pär Sparén and Lisen Arnheim Dahlström were involved in studies with unconditional grants from GSK and SPMSD. Jonas Hällgren has been involved in studies with unconditional grants from GSK. Corinne de Vries and Cormac Sammon hold research and consultancy contracts with GSK and with other pharmaceutical companies. MS, JD, Martijn Schuemie, Mees Mosseveld, and $\mathrm{SR}$ conduct occasionally unconditional research for pharmaceutical companies including Pfizer, Boehringer, Lilly, and AstraZeneca. Bart Jacobs has been involved in studies with unconditional grants from Baxter.

Ethical approval: In France, the case-control study was approved by the ethics committee of Toulouse (Comité de Protection des Personnes Sud Ouest et Outre Mer I et II) and participants (cases and controls) gave informed consent. In the Netherlands, the study was provided with a declaration of no objection from the medical ethics committee of the Erasmus University Medical Center in Rotterdam (MEC-2009-404). Subsequent amendments to collect data entirely anonymously through the GP allowed the inclusion of study subjects without requiring informed consent. In Denmark ethics approval was not required, though the National Board of Health approved chart review. In Sweden the study was approved by the regional ethics committee, Karolinska Institute, Stockholm, and participants gave written informed consent. In the UK, the GPRD Group has obtained ethical approval from a multicentre research ethics committee (MREC) for all purely observational research using GPRD data. Individual studies must be granted approval by an Independent Scientific Advisory Committee (ISAC). This study received ISAC approval (protocol No 10_058).

Data sharing: No additional data available.

1 Girard MP, Katz J, Pervikov Y, Palkonyay L, Kieny M-P. Report of the 6th meeting on the evaluation of pandemic influenza vaccines in clinical trials World Health Organisation Geneva, Switzerland, 17-18 February 2010. Vaccine 2010:28:6811-20.

2 Plennevaux E, Sheldon E, Blatter M, Reeves-Hoche MK, Denis M. Immune response after a single vaccination against 2009 influenza A H1N1 in USA: a preliminary report of two randomised controlled phase 2 trials. Lancet 2010;375:41-8.

3 Vajo Z, Tamas F, Sinka L, Jankovics I. Safety and immunogenicity of a 2009 pandemic influenza A H1N1 vaccine when administered alone or simultaneously with the seasonal influenza vaccine for the 2009-10 influenza season: a multicentre, randomised controlled trial. Lancet 2010;375:49-55.

4 Roman F, Vaman T, Gerlach B, Markendorf A, Gillard P, Devaster JM. Immunogenicity and safety in adults of one dose of influenza A H1N1v 2009 vaccine formulated with and without AS03A-adjuvant: preliminary report of an observer-blind, randomised trial. Vaccine 2010;28:1740-5.

5 Nolan T, McVernon J, Skeljo M, Richmond P, Wadia U, Lambert S, et al. Immunogenicity of a monovalent 2009 influenza $A(\mathrm{H} 1 \mathrm{~N} 1)$ vaccine in infants and children: a randomized trial. JAMA 2010;303:37-46

6 Oh CE, Lee J, Kang JH, Hong YJ, Kim YK, Cheong HJ, et al. Safety and immunogenicity of an inactivated split-virus influenza $\mathrm{A} / \mathrm{H} 1 \mathrm{~N} 1$ vaccine in healthy children from 6 months to $<18$ years of age: a prospective, open-label, multi-center trial. Vaccine 2010;28:5857-63.

7 Lu W, Tambyah PA. Safety and immunogenicity of influenza A H1N1 vaccines. Expert Rev Vaccines 2010;9:365-9.

8 Lu CY, Shao PL, Chang LY, Huang YC, Chiu CH, Hsieh YC, et al. Immunogenicity and safety of a monovalent vaccine for the 2009 pandemic influenza virus A (H1N1) in children and adolescents. Vaccine 2010;28:5864-70.

9 Schonberger LB, Bregman DJ, Sullivan-Bolyai JZ, Keenlyside RA, Ziegler DW, Retailliau $\mathrm{HF}$, et al. Guillain-Barre syndrome following vaccination in the National Influenza Immunization Program, United States, 1976-1977. Am J Epidemiol 1979;110:105-23.

10 Kaplan JE, Katona P, Hurwitz ES, Schonberger LB. Guillain-Barre syndrome in the United States, 1979-1980 and 1980-1981. Lack of an association with influenza vaccination. JAMA 1982;248:698-700.

11 Hurwitz ES, Schonberger LB, Nelson DB, Holman RC. Guillain-Barré syndrome and the 1978-1979 influenza vaccine. N Engl J Med 1981:304:1557-61.

12 Lasky T, Terracciano GJ, Magder L, Koski CL, Ballesteros M, Nash D, et al. The Guillain-Barré syndrome and the 1992-1993 and 1993-1994 influenza vaccines. N Engl J Med 1998;339:1797-802.

13 Juurlink DN, Stukel TA, Kwong J, Kopp A, McGeer A, Upshur RE, et al. Guillain-Barré syndrome after influenza vaccination in adults: a population-based study. Arch Intern Med 2006;166:2217-21

14 Sejvar JJ, Kohl KS, Gidudu J, Amato A, Bakshi N, Baxter R, et al. Guillain-Barré syndrome and Fisher syndrome: case definitions and guidelines for collection, analysis, and presentation of immunization safety data. Vaccine 2010;29:599-612.

15 Vucic S, Kiernan MC, Cornblath DR. Guillain-Barré syndrome: an update. J Clin Neurosci 2009;16:733-41

16 Jacobs BC, Rothbarth PH, van der Meche FG, Herbrink P, Schmitz PI, de Klerk MA, et al. The spectrum of antecedent infections in Guillain-Barré syndrome: a case-control study. Neurology 1998;51:1110-5.

17 Van Doorn PA, Ruts L, Jacobs BC. Clinical features, pathogenesis, and treatment of Guillain-Barré syndrome. Lancet Neurol 2008;7:939-50.

18 McGrogan A, Madle G, Seaman H, de Vries C. The epidemiology of Guillain-Barre syndrome worldwide. A systematic literature review. Neuroepidemiology 2009;32:150-63

19 Rees J, Thompson R, Smeeton N, Hughes R. Epidemiological study of Guillain-Barré syndrome in south east England. J Neurol Neurosurg Psychiatry 1998;64:74-7.

20 Hughes RA, Rees JH. Clinical and epidemiologic features of Guillain-Barré syndrome. $J$ Infect Dis 1997;176(suppl 2):S92-8. 
21 Tam CC, O'Brien SJ, Petersen I, Islam A, Hayward A, Rodrigues LC. Guillain-Barré syndrome and preceding infection with campylobacter, influenza and Epstein-Barr virus in the general practice research database. PLoS One 2007;2:e344.

22 Weise MJ, Carnegie PR. An approach to searching protein sequences for superfamily relationships or chance similarities relevant to the molecular mimicry hypothesis: application to the basic proteins of myelin. J Neurochem 1988;51:1267-73.

23 Nachamkin I, Shadomy SV, Moran AP, Cox N, Fitzgerald C, Ung H, et al. Anti-ganglioside antibody induction by swine (A/NJ/1976/H1N1) and other influenza vaccines: insights into vaccine-associated Guillain-Barré syndrome. J Infect Dis 2008;198:226-33.

24 Stowe J, Andrews N, Wise L, Miller E. Investigation of the temporal association of Guillain-Barré syndrome with influenza vaccine and influenza-like illness using the United Kingdom General Practice Research Database. Am J Epidemiol 2009;169:382-8.

25 Lehmann HC, Hartung HP, Kieseier BC, Hughes RA. Guillain-Barré syndrome after exposure to influenza virus. Lancet Infect Dis 2010;10:643-51.

26 Coloma P, Schuemie M, Trifirò G, Gini R, Herings R, Hippisley-Cox J, et al. Combining electronic healthcare databases in Europe to allow for large-scale drug safety monitoring: the EU-ADR Project. Pharmacoepidemiol Drug Saf 2011;20:1-11.

27 Greenland S. Modeling and variable selection in epidemiologic analysis. Am J Pub Health 1989;70:340-9.

28 Fleis J. The statistical basis of meta-analysis. Stat Methods in Med Res 1993;2:121-45.
29 Preliminary results: surveillance for Guillain-Barré syndrome after receipt of influenza A (H1N1) 2009 monovalent vaccine-United States, 2009-2010. MMWR Morb Mortal Wkly Rep 2010;59:657-61.

30 Greene SK, Kulldorff M, Lewis EM, Li R, Yin R, Weintraub ES, et al. Near real-time surveillance for influenza vaccine safety: proof-of-concept in the Vaccine Safety Datalink Project. Am J Epidemiol 2010;171:177-88.

31 Hemachudha T, Griffin DE, Chen WW, Johnson RT. Immunologic studies of rabies vaccination-induced Guillain-Barré syndrome. Neurology 1988;38:375-8.

32 Piyasirisilp S, Hemachudha T. Neurological adverse events associated with vaccination. Piyasirisilp S, Hemachudha T. N
Curr Opin Neurol 2002;15:333-8

33 Haber $P$, Sejvar J, Mikaeloff $Y$, DeStefano F. Vaccines and Guillain-Barré syndrome. Drug Saf 2009;32:309-23.

34 Haber P, DeStefano F, Angulo FJ, Iskander J, Shadomy SV, Weintraub E, et al. Guillain-Barré syndrome following influenza vaccination. JAMA 2004;292:2478-81.

35 Roscelli JD, Bass JW, Pang L. Guillain-Barré syndrome and influenza vaccination in the US Army, 1980-1988. Am J Epidemiol 1991;133:952-5.

Accepted: 9 May 2011

Cite this as: BMJ 2011;343:d3908 


\section{Tables}

Table 1| Sources for cases, controls, exposure, and covariates by country in study of association between pandemic influenza A (H1N1) 2009 vaccine and Guillain-Barré syndrome

\begin{tabular}{|c|c|c|c|c|c|}
\hline Country & Cases & Controls & Matching & $\begin{array}{l}\text { Exposure to } \mathrm{H} 1 \mathrm{~N} 1 \\
\text { vaccination }\end{array}$ & Covariates \\
\hline UK & $\begin{array}{l}\text { Each case identified from GPRD by using } \\
\text { appropriate READ codes (F370.00, F370000, } \\
\text { F370100, F370200, F370z00). Case verification } \\
\text { done with free text, scanned hospital letters as } \\
\text { well as GPs' notes regarding diagnostic } \\
\text { procedures. No major selection bias expected }\end{array}$ & $\begin{array}{l}\text { Controls selected randomly from } \\
\text { GPRD, matched on age, sex, practice, } \\
\text { and index date to case. Consent not } \\
\text { required. No selection bias expected }\end{array}$ & $\begin{array}{l}\text { Sex, age, } \\
\text { practice, } \\
\text { index date }\end{array}$ & $\begin{array}{l}\text { From automated GP } \\
\text { records, no recall bias. } \\
\text { Non-differential } \\
\text { misclassification possible } \\
\text { as some people might } \\
\text { have been vaccinated } \\
\text { outside of GP office }\end{array}$ & $\begin{array}{l}\text { From GP record } \\
\text { for cases and } \\
\text { controls }\end{array}$ \\
\hline Denmark & $\begin{array}{l}\text { Cases identified from National Patient Register } \\
\text { with primary discharge diagnoses only (ICD-10 } \\
\text { code: G61.0). Case verification done after } \\
\text { obtaining charts from cases. Potential small } \\
\text { selection bias because of incomplete availability } \\
\text { of charts }\end{array}$ & $\begin{array}{l}\text { Controls selected randomly from } \\
\text { Danish civil registration system. Up to } \\
20 \text { controls matched to case on age, } \\
\text { sex, and index date. Consent not } \\
\text { required. No selection bias expected }\end{array}$ & $\begin{array}{l}\text { Sex, age, } \\
\text { index date }\end{array}$ & $\begin{array}{l}\text { From vaccination } \\
\text { registry, no recall bias }\end{array}$ & $\begin{array}{l}\text { From medical } \\
\text { charts for cases } \\
\text { only) }\end{array}$ \\
\hline Netherlands & $\begin{array}{l}\text { Cases identified prospectively through } \\
\text { neurologists. Completeness verified } \\
\text { retrospectively by checking against claims codes } \\
\text { in each of reporting hospitals. Consent not } \\
\text { required. Missing patients included retrospectively } \\
\text { as far as possible. Verification of reporting against } \\
\text { vaccination status showed incomplete reporting } \\
\text { but non-differential regarding vaccinations }\end{array}$ & $\begin{array}{l}\text { Controls were identified from GP of } \\
\text { case patients. } 10 \text { patients randomly } \\
\text { selected from list of registered patients } \\
\text { and matched to case on age, sex, } \\
\text { index date, and practice. Consent not } \\
\text { required. No selection bias expected }\end{array}$ & $\begin{array}{l}\text { Sex, age, } \\
\text { practice, } \\
\text { index date }\end{array}$ & $\begin{array}{l}\text { From GP record. No } \\
\text { recall bias } \\
\text { Non-differential } \\
\text { misclassification possible } \\
\text { as some people might } \\
\text { have been vaccinated } \\
\text { outside of GP office }\end{array}$ & $\begin{array}{l}\text { From GP records } \\
\text { for cases and } \\
\text { controls }\end{array}$ \\
\hline France & $\begin{array}{l}\text { Cases identified prospectively through } \\
\text { neurologists in seven reference hospitals in } \\
\text { France. Patients needed to provide informed } \\
\text { consent. Completeness verified against pharmacy } \\
\text { data (immunoglobulin prescriptions) and showed } \\
\text { incomplete reporting ( }<50 \% \text { ). Vaccination status } \\
\text { of non-reported cases could not be verified as } \\
\text { linkage to vaccination registry required consent }\end{array}$ & $\begin{array}{l}\text { Controls obtained from trauma unit in } \\
\text { same hospital. Controls needed to } \\
\text { provide informed consent. Response } \\
\text { incomplete. Not possible to assess } \\
\text { whether non-response differed by } \\
\text { vaccination status and hence cannot } \\
\text { exclude selection bias }\end{array}$ & $\begin{array}{l}\text { Sex, age, } \\
\text { hospital, } \\
\text { index date }\end{array}$ & $\begin{array}{l}\text { From registry. No recall } \\
\text { bias }\end{array}$ & $\begin{array}{l}\text { Medical records } \\
\text { for both cases and } \\
\text { controls }\end{array}$ \\
\hline Sweden & $\begin{array}{l}\text { Cases identified through seven neurology } \\
\text { assessment laboratories where cases are } \\
\text { laboratory confirmed for population of } 9.4 \text { million. } \\
\text { Informed consent needed from all cases. } \\
\text { Completeness of cases was checked in National } \\
\text { Patient Registry for part of country. Recruitment } \\
\text { incomplete because of delays in consent and } \\
\text { non-consent. Not possible to assess whether this } \\
\text { non-response differed by vaccination status and } \\
\text { hence cannot exclude selection bias }\end{array}$ & $\begin{array}{l}\text { Controls selected randomly from } \\
\text { Swedish national population registry. } \\
\text { Controls needed to provide informed } \\
\text { consent. Response incomplete. Not } \\
\text { possible to assess whether } \\
\text { non-response differed by vaccination } \\
\text { status and hence cannot exclude } \\
\text { selection bias }\end{array}$ & $\begin{array}{l}\text { Sex, age, } \\
\text { index date }\end{array}$ & $\begin{array}{l}\text { By interview, cannot } \\
\text { exclude recall bias }\end{array}$ & $\begin{array}{l}\text { By interview for } \\
\text { cases and } \\
\text { controls. Charts } \\
\text { reviewed for case } \\
\text { verification }\end{array}$ \\
\hline
\end{tabular}




\begin{tabular}{|c|c|c|c|c|c|c|}
\hline & Netherlands & Sweden & $\mathrm{UK}^{*}$ & Denmark $\uparrow$ & France & Pooled \\
\hline Brand used & $\begin{array}{l}\text { Focetria (Pandemrix in } \\
\text { children) }\end{array}$ & Pandemrix & $\begin{array}{l}\text { Pandemrix (Celvapan, } \\
\text { Focetria) }\end{array}$ & Pandemrix & $\begin{array}{l}\text { Pandemrix (Celvapan, } \\
\text { Focetria, Panenza) }\end{array}$ & - \\
\hline Vaccination coverage $(\%) \ddagger$ & 33 & 62 & 8 & 6 & $7-8$ & \\
\hline $\begin{array}{l}\text { Approximate source population } \\
\text { (million) }\end{array}$ & 16 & 9.4 & 3.5 & 5.5 & $10-20$ & 49.4 \\
\hline Expected No of cases in study period§ & 100 & 59 & 22 & 34 & $62-25$ & 299 \\
\hline No of cases recruited & 33 & 26 & 34 & 24 & 37 & 154 \\
\hline No of cases with $\geq 1$ control & 25 & 18 & 30 & 24 & 7 & 104 \\
\hline Total No of controls & 227 & 60 & 300 & 590 & 21 & 1198 \\
\hline Total study population & 252 & 78 & 330 & 614 & 28 & 1302 \\
\hline \multicolumn{7}{|c|}{ Characteristics of cases (No (\%) unless stated otherwise) } \\
\hline Mean (SD) age (years) & $46(23)$ & $55(20)$ & $48(23)$ & $48(19)$ & $61(16)$ & $50(22)$ \\
\hline Age $\leq 18$ & $4(16)$ & 0 & $4(13)$ & $1(4)$ & 0 & $9(9)$ \\
\hline Age $19-59$ & $13(52)$ & $9(50)$ & $16(53)$ & $16(67)$ & $3(43)$ & $57(55)$ \\
\hline Age $\geq 60$ & $8(32)$ & $9(50)$ & $10(33)$ & $7(29)$ & $4(57)$ & $38(37)$ \\
\hline Male & $14(56)$ & $13(73)$ & $17(57)$ & $14(57)$ & $4(58)$ & $62(60)$ \\
\hline \multicolumn{7}{|l|}{ Brighton Collaboration case classification: } \\
\hline Level 1 & $10(40)$ & $11(61)$ & 0 & $7(29)$ & $4(57)$ & $32(31)$ \\
\hline Level 2 & $10(40)$ & $3(17)$ & 0 & $8(33)$ & $2(29)$ & $23(22)$ \\
\hline Level 3 & $3(12)$ & $4(22)$ & 0 & $3(13)$ & 0 & $10(10)$ \\
\hline $\begin{array}{l}\text { Neurologist confirmed but not level } \\
1-3\end{array}$ & $2(8)$ & 0 & $30(100)$ & $6(25)$ & $1(14)$ & $39(38)$ \\
\hline \multicolumn{7}{|c|}{$\begin{array}{l}\text { *UK stopped recruitment of cases and controls for case-control study on } 2 \text { Feb } 2010 . \\
\text { †Register from which cases identified in Denmark ran until end of December } 2009 . \\
\text { †Based on VENICE data. } \\
\text { §Based on } 1.5 \text { per } 100000 \text { person years (IR) and } 5 \text { month study period: IR*source popt }\end{array}$} \\
\hline
\end{tabular}


Table 3| Distribution of chronic comorbidity and infections in cases and controls by country in study of association between pandemic influenza A (H1N1) 2009 vaccine and Guillain-Barré syndrome. Figures are numbers (percentages)

\begin{tabular}{|c|c|c|c|c|c|c|c|c|c|c|}
\hline & \multicolumn{2}{|c|}{ Netherlands } & \multicolumn{2}{|c|}{ Sweden } & \multicolumn{2}{|c|}{ UK } & \multicolumn{2}{|c|}{ France } & \multicolumn{2}{|c|}{ Denmark } \\
\hline & $\begin{array}{l}\text { Control } \\
(n=227)\end{array}$ & $\begin{array}{l}\text { Case } \\
(n=25)\end{array}$ & Control $(n=60)$ & $\begin{array}{c}\text { Case } \\
(n=18)\end{array}$ & $\begin{array}{l}\text { Control } \\
(n=300)\end{array}$ & $\begin{array}{c}\text { Case } \\
(n=30)\end{array}$ & $\begin{array}{l}\text { Control } \\
(n=21)\end{array}$ & $\begin{array}{l}\text { Case } \\
(n=7)\end{array}$ & $\begin{array}{l}\text { Control } \\
(n=590)^{*}\end{array}$ & $\begin{array}{l}\text { Case } \\
(n=24)\end{array}$ \\
\hline \multicolumn{11}{|l|}{ Chronic comorbidity } \\
\hline $\begin{array}{l}\text { Autoimmune } \\
\text { disease }\end{array}$ & $6(3)$ & $2(8)$ & $4(7)$ & 0 & $47(16)$ & $8(27)$ & 0 & 0 & NA & 0 \\
\hline $\begin{array}{l}\text { History of } \\
\text { Guillain-Barré }\end{array}$ & 0 & $1(4)$ & 0 & 0 & 0 & $1(3)$ & 0 & 0 & NA & $1(4)$ \\
\hline Epstein Barr virus & $12(5)$ & $2(8)$ & 0 & 0 & $1(0.3)$ & $1(3)$ & 0 & 0 & NA & 0 \\
\hline Malignancy & $12(5)$ & $1(4)$ & $4(7)$ & $2(11)$ & $16(5)$ & $2(7)$ & $3(14)$ & $1(14)$ & NA & $1(4)$ \\
\hline $\begin{array}{l}\text { Immune } \\
\text { compromised }\end{array}$ & $5(2)$ & $1(4)$ & 0 & $1(6)$ & $26(9)$ & $4(13)$ & $2(10)$ & 0 & NA & 0 \\
\hline \multicolumn{11}{|c|}{ Infections in 6 weeks before } \\
\hline $\begin{array}{l}\text { Gastrointestinal } \\
\text { infection }\end{array}$ & $1(0.4)$ & $2(8)$ & $1(2)$ & $4(22)$ & 0 & 0 & 0 & $2(29)$ & NA & $2(8)$ \\
\hline Influenza-like illness & $3(1)$ & $8(32)$ & 0 & $2(11)$ & $1(0.3)$ & 0 & 0 & 0 & NA & $4(17)$ \\
\hline $\begin{array}{l}\text { Upper respiratory } \\
\text { tract infection }\end{array}$ & $10(4)$ & $8(32)$ & $3(5)$ & $4(22)$ & $11(4)$ & $5(17)$ & 0 & $2(29)$ & NA & 0 \\
\hline $\begin{array}{l}\text { Influenza-like illness } \\
\text { or upper respiratory } \\
\text { tract infection (\%) }\end{array}$ & $13(6)$ & $12(48)$ & $3(5)$ & $6(33)$ & $12(4)$ & $5(17)$ & 0 & $2(29)$ & NA & $4(17)$ \\
\hline
\end{tabular}


Table 4 | Influenza vaccinations in cases and controls according to timing of vaccination ( $\leq 6$ weeks or $>6$ weeks) before onset of symptoms and brand. Figures are numbers (percentages)

\begin{tabular}{|c|c|c|c|c|c|c|c|c|c|c|}
\hline & \multicolumn{2}{|c|}{ Netherlands } & \multicolumn{2}{|c|}{ Sweden } & \multicolumn{2}{|c|}{ UK } & \multicolumn{2}{|c|}{ France } & \multicolumn{2}{|c|}{ Denmark } \\
\hline & Control & Case & Control & Case & Control & Case & Control & Case & Control & Case \\
\hline \multicolumn{11}{|c|}{ Pandemic influenza A (H1N1) 2009 vaccine } \\
\hline None & $149(66)$ & $13(52)$ & $23(38)$ & $7(39)$ & $279(93)$ & $28(93)$ & $20(95)$ & $5(71)$ & $568(96)$ & $20(83)$ \\
\hline$\leq 6$ weeks ${ }^{*}$ & $33(15)$ & $6(24)$ & $11(18)$ & $6(33)$ & $16(5)$ & $2(7)$ & 0 & $1(14)$ & $6(1)$ & $2(8)$ \\
\hline \multicolumn{11}{|l|}{ Dose: } \\
\hline 1 dose & $26(12)$ & $2(8)$ & $11(18)$ & $6(33)$ & $16(5)$ & $2(7)$ & 0 & 0 & $6(1)$ & $2(8)$ \\
\hline 2 doses & $7(3)$ & $4(16)$ & 0 & 0 & $2(2)$ & 0 & 0 & $1(14)$ & 0 & 0 \\
\hline \multicolumn{11}{|l|}{ Brand: } \\
\hline Pandemrix & 0 & 0 & $11(18)$ & $6(33)$ & $13(4)$ & $2(7)$ & 0 & 0 & $6(1)$ & $2(8)$ \\
\hline Focetria & $33(15)$ & $6(24)$ & 0 & 0 & 0 & 0 & 0 & 0 & 0 & 0 \\
\hline Panenza & 0 & 0 & 0 & 0 & 0 & 0 & 0 & $1(14)$ & 0 & 0 \\
\hline Unknown & 0 & 0 & 0 & 0 & $3(1)$ & 0 & 0 & 0 & 0 & 0 \\
\hline$>6$ weeks $\dagger$ & $42(19)$ & $6(24)$ & $14(23)$ & $4(22)$ & $5(2)$ & 0 & 0 & 0 & $16(3)$ & $2(8)$ \\
\hline Unknown timing & $3(1)$ & 0 & $12(20)$ & $1(6)$ & 0 & 0 & $1(5)$ & $1(14)$ & 0 & 0 \\
\hline \multicolumn{11}{|c|}{ Seasonal influenza vaccination } \\
\hline None & $145(64)$ & $13(52)$ & $53(88)$ & $18(100)$ & $222(74)$ & $19(63)$ & 0 & 0 & NA & 0 \\
\hline$\leq 6$ weeks ${ }^{*}$ & $24(11)$ & $2(8)$ & $2(3)$ & 0 & $28(9)$ & $7(23)$ & 0 & 0 & NA & 0 \\
\hline$>6$ weeks $\dagger$ & $57(25)$ & $10(40)$ & $3(5)$ & 0 & $50(17)$ & $4(13)$ & 0 & 0 & NA & 0 \\
\hline Unknown timing & $1(0.4)$ & 0 & $2(3)$ & 0 & 0 & 0 & 0 & 0 & NA & 0 \\
\hline
\end{tabular}


Table 5 Crude and adjusted relative risk estimates (odds ratio and $95 \%$ confidence intervals) for Guillain-Barré syndrome after pandemic influenza A (H1N1) 2009 vaccination according to timing of vaccination ( $\leq 6$ weeks or $>6$ weeks) before onset of symptoms

\begin{tabular}{|c|c|c|c|c|}
\hline & Unadjusted matched analysis ${ }^{*}$ & ILI/URTI adjusted only & $\begin{array}{l}\text { Adjusted for seasonal influenza } \\
\text { vaccination only }\end{array}$ & $\begin{array}{l}\text { Adjusted for seasonal influenza } \\
\text { vaccination and ILI/URTI }\end{array}$ \\
\hline \multicolumn{5}{|l|}{ Denmark: } \\
\hline None & Reference & - & - & - \\
\hline$\leq 6$ weeks & 9.5 (1.7 to 53$)$ & - & - & - \\
\hline$>6$ weeks & $3.4(0.7$ to 17$)$ & - & - & - \\
\hline \multicolumn{5}{|l|}{ Netherlands: } \\
\hline None & Reference & Reference & Reference & Reference \\
\hline$\leq 6$ weeks & $2.5(0.7$ to 9.3$)$ & $1.3(0.3$ to 6.1$)$ & $1.7(0.3$ to 8.8$)$ & $0.6(0.1$ to 4.4$)$ \\
\hline 1 dose & $0.7(0.1$ to 6.0$)$ & $0.2(0.0$ to 4.2$)$ & $0.5(0.1$ to 5.1$)$ & 0.2 (0.01 to 4.3$)$ \\
\hline 2 doses & $6.8(1.3$ to 36$)$ & 5.3 (0.6 to 44.1$)$ & $6.2(1.1$ to 35.4$)$ & $6.9(0.6$ to 81.0$)$ \\
\hline$>6$ weeks & $1.7(0.4$ to 6.4$)$ & $0.9(0.2$ to 4.2$)$ & $0.7(0.1$ to 4.8$)$ & $0.2(0.02$ to 1.6$)$ \\
\hline Missing dates & NC & NC & NC & NC \\
\hline \multicolumn{5}{|l|}{ Swedent: } \\
\hline None & Reference & Reference & Reference $†$ & Reference $†$ \\
\hline$\leq 6$ weeks & $2.3(0.5$ to 11.7$)$ & $1.8(0.3$ to 10.7$)$ & $2.4(0.5$ to 11.8$)$ & $1.8(0.3$ to 12$)$ \\
\hline$>6$ weeks & $0.9(0.2$ to 4.9$)$ & $1.0(0.2$ to 6.3$)$ & $1.2(0.2$ to 6.3$)$ & $1.3(0.2$ to 8.5$)$ \\
\hline Missing date & 0.3 (0.03 to 3.5$)$ & $0.5(0.0$ to 5.5$)$ & $0.4(0.0$ to 4.0$)$ & 0.6 (0.1 to 6.8$)$ \\
\hline \multicolumn{5}{|l|}{ UK: } \\
\hline None & Reference & Reference & Reference & Reference \\
\hline$\leq 6$ weeks & $1.3(0.3$ to 6.4$)$ & $1.1(0.2$ to 5.7$)$ & $0.7(0.1$ to 4.2$)$ & $0.7(0.1$ to 4.1$)$ \\
\hline$>6$ weeks & $\mathrm{NC}$ & NC & $\mathrm{NC}$ & $\mathrm{NC}$ \\
\hline
\end{tabular}

ILI/URTI=influenza-like illness or upper respiratory tract infection; NC=not calculated because of low numbers.

${ }^{*}$ Matched on age (within 1 year), sex, and index date; additionally matched on GP practice in Netherlands and UK

†No cases exposed to seasonal influenza vaccination (possible under-reporting). 
Table 6 | Crude and adjusted relative risk estimates (odds ratio and $95 \%$ confidence intervals) from pooled analyses for Guillain-Barré syndrome after pandemic influenza A (H1N1) 2009 vaccination given $\leq 6$ weeks before onset of symptoms

\begin{tabular}{|c|c|c|c|c|}
\hline & Unadjusted matched analysis* & ILI/URTI adjusted only & $\begin{array}{l}\text { Adjusted for seasonal influenza } \\
\text { vaccination only }\end{array}$ & $\begin{array}{l}\text { Adjusted for seasonal influenza } \\
\text { vaccination and ILI/URTI }\end{array}$ \\
\hline \multicolumn{5}{|l|}{ No exposure as reference } \\
\hline $\begin{array}{l}\text { Netherlands, UK, Sweden, } \\
\text { Denmark }\end{array}$ & 2.8 (1.3 to 6.0$)$ & - & - & - \\
\hline Netherlands, UK, Sweden & $2.0(0.9$ to 4.8$)$ & $1.4(0.5$ to 3.5$)$ & $1.5(0.6$ to 3.9$)$ & $1.0(0.3$ to 2.7$)$ \\
\hline Netherlands, UK & $1.9(0.7$ to 5.3$)$ & $1.2(0.4$ to 3.7$)$ & $1.2(0.4$ to 3.8$)$ & $0.7(0.2$ to 2.5$)$ \\
\hline \multicolumn{5}{|c|}{ Restricted to people without ILI/URTI; no exposure as reference } \\
\hline Netherlands, UK, Sweden & $1.9(0.7$ to 5.6$)$ & - & $1.2(0.4$ to 4.0$)$ & - \\
\hline Netherlands, UK & $2.5(0.6$ to 10.7$)$ & - & $1.2(0.3$ to 5.8$)$ & - \\
\hline
\end{tabular}

ILI/URTI=influenza-like illness or upper respiratory tract infection.

*Matched on age (within 1 year), sex, and index date; additionally matched on GP practice in Netherlands and UK. 